\title{
Deviant Morphology of the Root Canal System in Mandibular Premolars: Clinical Cases
}

\author{
Kostadin Georgiev, Aleksandra Pecheva \\ Department of Operative Dentistry and Endodontics, Faculty of Dental Medicine, Medical University of Plovdiv, Plovdiv, Bulgaria
}

Corresponding author: Kostadin Georgiev, Department of Operative Dentistry and Endodontics, Faculty of Dental Medicine, Medical University of Plovdiv, 3 Hristo Botev Blvd., Plovdiv, Bulgaria; E-mail: kostadin.georgiev@mu-plovdiv.bg; Tel.: +359 883453823

Received: 22 Sep 2020 Accepted: 13 Jan 2021 Published: 28 Feb 2022

Citation: Georgiev K, Pecheva A. Deviant morphology of the root canal system in mandibular premolars: clinical cases. Folia Med (Plovdiv) 2022;64(1):176-80. doi: 10.3897/folmed.64.e58877.

\begin{abstract}
Numerous cases of aberrant root and root canal morphology have been described, still diversion occurs more frequently in premolars and molars. To the dental researcher, the aberrations in the mandibular second premolars afford a vast field of interest. The current report presents a clinical case which demonstrates a simplified therapeutic protocol for re-treatment of Vertucci type V root canals. Endodontic access is gained by expanding the endodontic cavity. The instrumentation (preflaring and final preparation) of the root canal system is performed using predominantly hand files in order to preserve to the maximum the tactile feedback in the apical part of the ramification. Obturation is performed through hydraulic condensation. Postoperative radiographs show sufficient three-dimensional sealing of all portals of exit with excellent healing result.
\end{abstract}

\section{Keywords}

aberrant root, deviant anatomy, Vertucci Type V

\section{INTRODUCTION}

In-depth knowledge of root canal morphology and its variations is an essential prerequisite for a successful endodontic treatment. ${ }^{1}$

Root canals often show a spectrum of different variations as they reach the apical foramen. Regarding these facts, in a 2400-extracted-teeth study, Vertucci et al. managed to classify the variety of root canal configurations into eight distinct types (Fig. 1). It is evident from the collected data that premolars and molars show a high frequency of deviation. $^{2-5}$

The endodontic treatment of mandibular premolars presents a clinical challenge due to the often complex, various, and multiform root canal system of these teeth. The anatomy of these teeth is often aberrated by accessory root canals, deltas, and lateral ramifications. Occurrence of two, three, and even four-rooted configurations of premolars has been described. ${ }^{4-7}$

\section{CASE REPORTS}

\section{Case 1}

The current case reports present uncommon root canal system aberrations - Vertucci type V configuration (2.5\%, Vertucci et al.) in mandibular premolars. The first case is a 51-yearold female patient complaining of localized dull pain on mastication and numbness in tooth \#35. The tooth had been endodontically treated seven months prior to the visit. The clinical examination revealed disto-occlusal cavity in tooth \#35 restored with a temporary filling. Vitality was measured by an electric pulp test (EPT), and no response was registered to cold and hot stimuli. The tooth was tender to percussion. Preoperative radiograph revealed atypical Vertucci type $V$ root canal configuration in teeth \#34 and \#35 with an accessory canal diverting from the main one in the apical third. The radiograph also showed incomplete endodontic treat- 


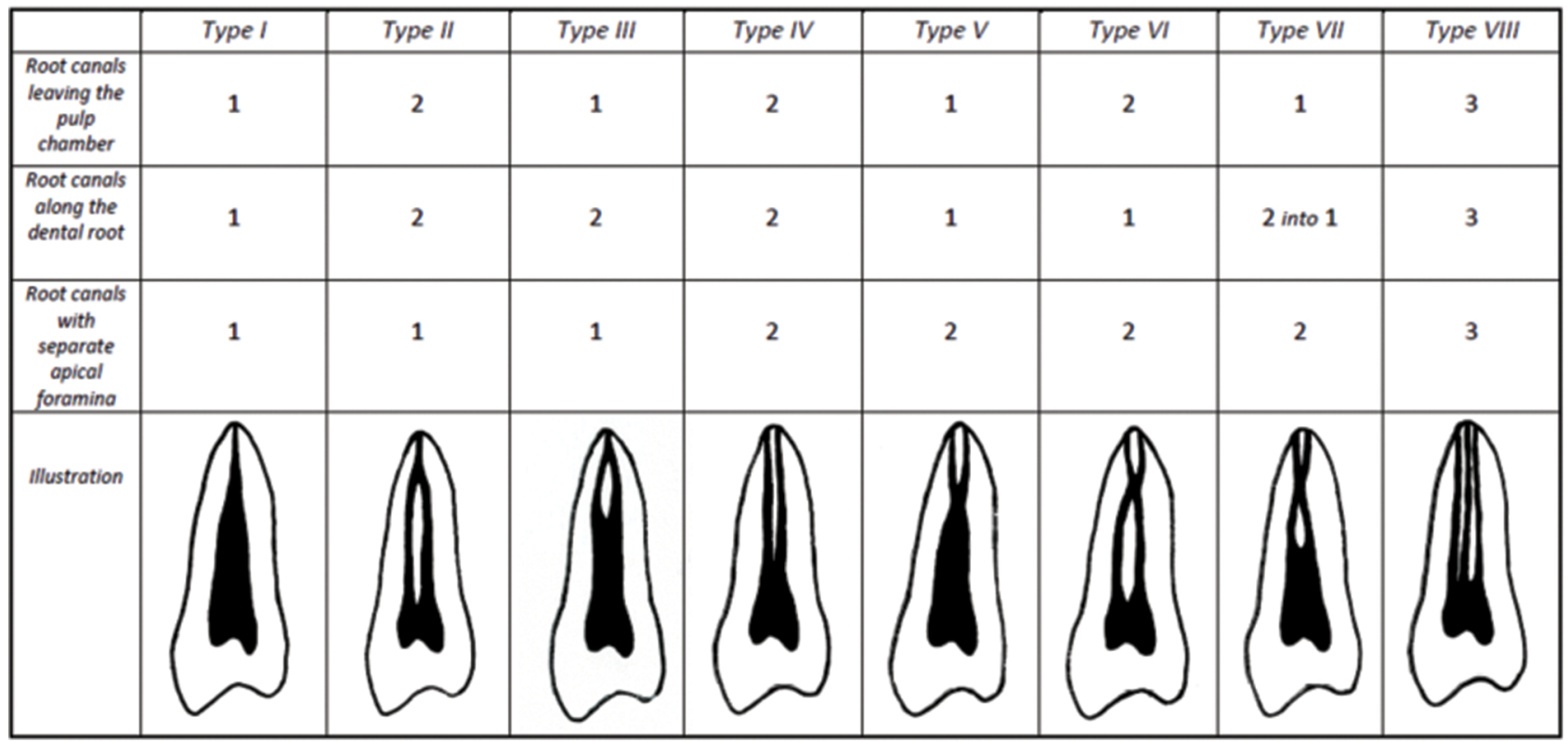

Figure 1. Vertucci root-canal configurations. Adapted from Georgiev K. \& Tanev M.

ment with presence of diffuse periapical radiolucency (Fig. $2 A$ ). The condition was diagnosed as asymptomatic apical periodontitis (AAE Diagnostic Terminology).

\section{Case 2}

The second case is a 41-year-old male patient with a chief complaint of acute, constant pain in tooth \#44 (Fig. 3). His medical history was non-contributory. The clinical examination revealed extensive carious lesion below the clinical tooth equator. Vitality tests showed negative response to cold and hot stimuli as well as negative reaction to an electric stimulus (electric pulp test, EPT); pain was registered on palpation and percussion. The observed condition was diagnosed as symptomatic apical periodontitis (AAE Diagnostic Terminology).

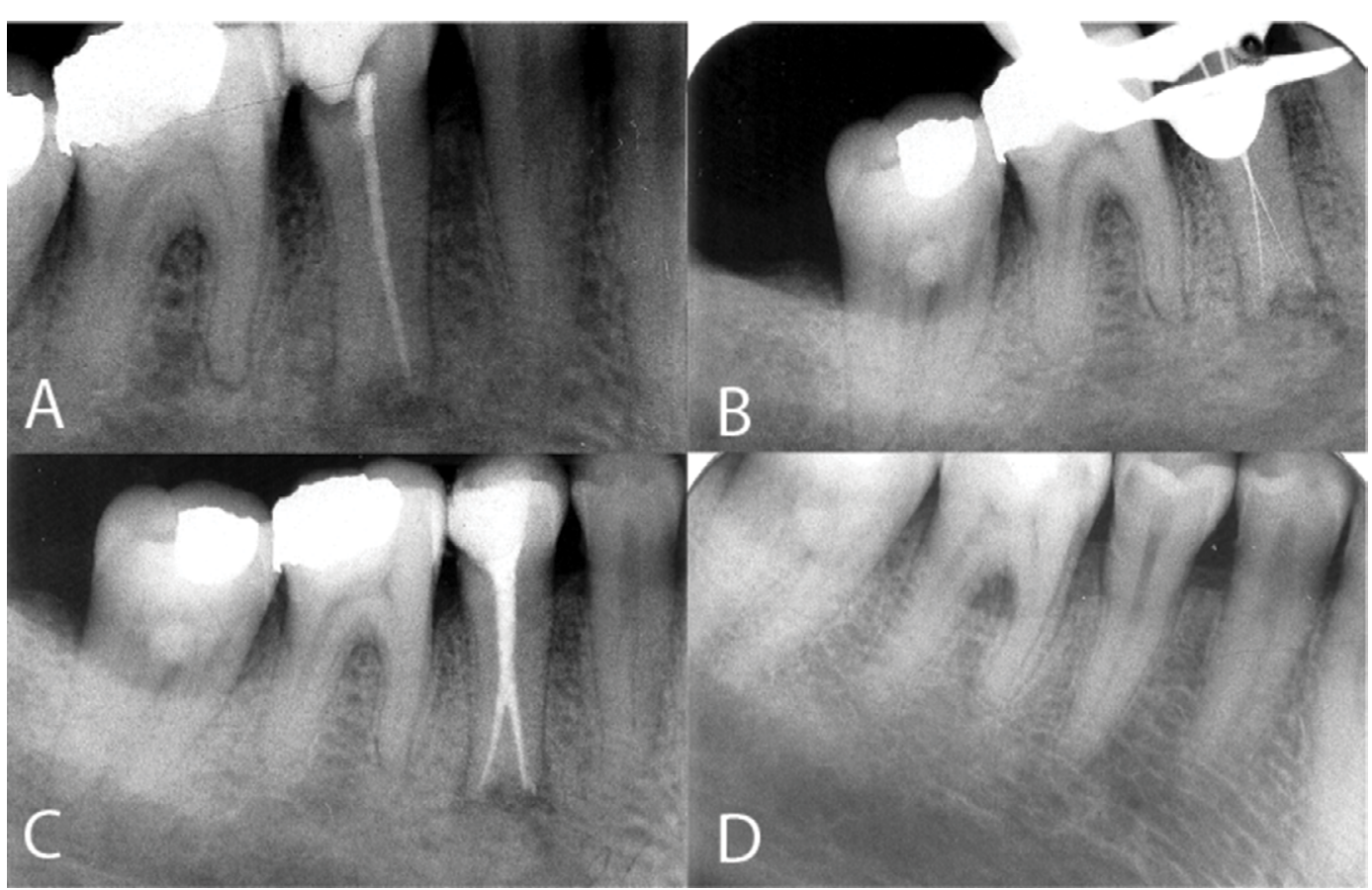

Figure 2. A. Preoperative radiograph of Case 1 showing Vertucci type V root canal configuration; B. Working radiograph: two instruments are inserted in the vestibular and lingual canals. The site of bifurcation of the canal is clearly seen; C. Postoperative radiograph: the main and accessory root canals have been successfully filled. D. Diagnostic radiograph of the opposite mandibular segment: Vertucci type $\mathrm{V}$ root canal anatomy is found in tooth \#44 as well. 


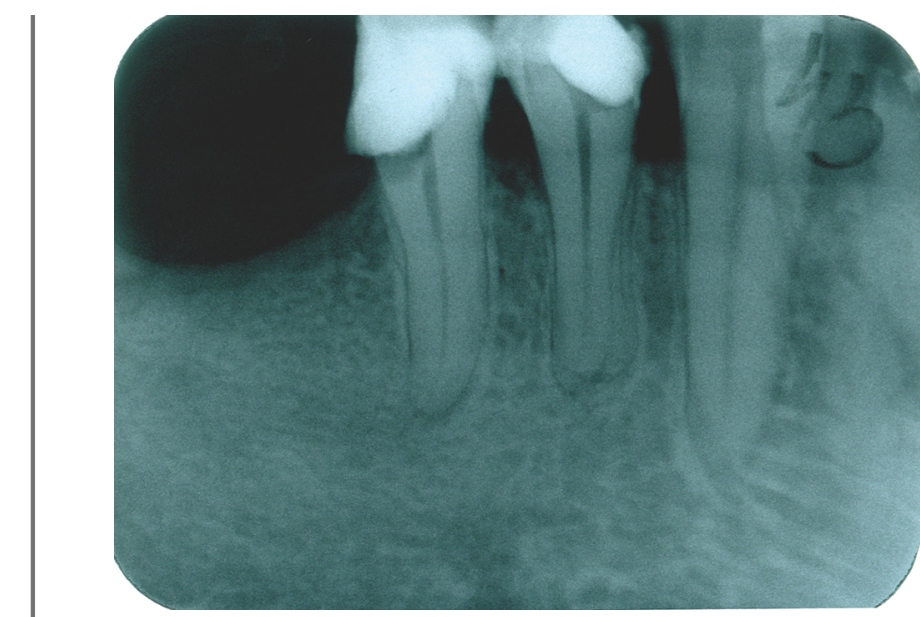

Figure 3. Preoperative X-ray of tooth \#44.

\section{Treatment protocol}

The teeth in both cases were isolated with rubber dam and the root canal treatment was completed following a standard protocol of chemo-mechanical instrumentation. To gain sufficient access to the root canals, the conventional access was modified and prepared with wider vestibulo-lingual diameter of the access cavity using access burs (Dentsply MAILEFER USA). The irrigation protocol consists of $2.5 \%$ sodium hypochlorite and saline, followed by ultrasonic activation and 17\% EDTA. A pre-curved ISO \#08 K-file was used to utilize tactile feedback in the root canal system. Upon thorough tactile exploration of the endodontic space, a split was detected at the lingual wall in the apical third of the main canal. The accessory canal separated from the main canal at a nearly 90-degree angle. The file was pushed into the additional lingual canal. The working length was determined by an apex locator (Raypex 6, VDV GmbH) and confirmed by a radiograph (Figs $\mathbf{2 B}, \mathbf{4})$.

The accessory canals were cleaned and shaped sequentially with pre-curved K-files \#10-30 (Dentsply MAILEFER USA) using a standard technique. Rotary files are not used to avoid possible loss of access to the accessory canals. Following

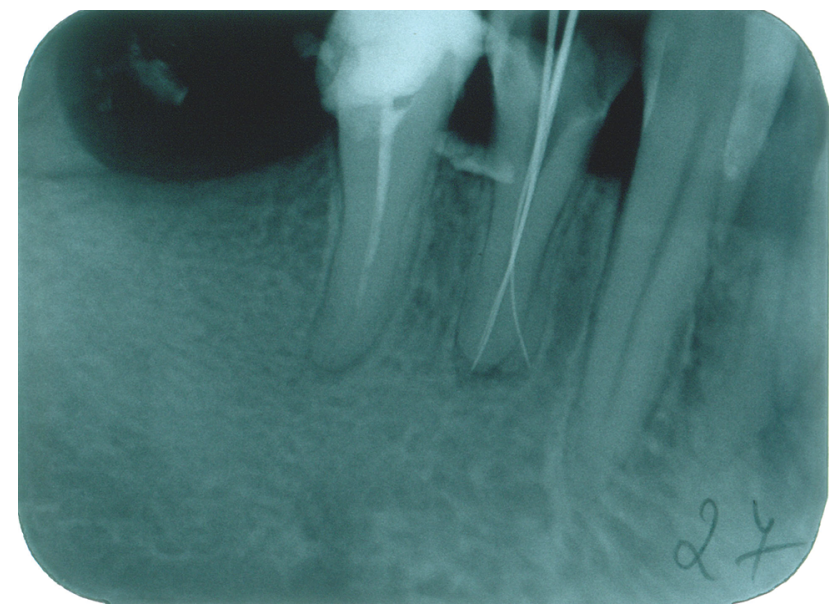

Figure 4. Working length confirmation by a radiograph. the mechanical preparation of the root canal system and final irrigation with $0.9 \% \mathrm{NaCl}$, the root canals were dried with sterile paper points and obturated with gutta-percha and $A H$ Plus sealer (Dentsply MAILEFER USA) using a hydraulic condensation technique. The accessory canals were coated first with AH plus sealer (Dentsply) using a K-reamer \#25. A calibrated \#30 (.02) gutta-percha point was dipped in $75 \%$ alcohol and hand pre-curved before insertion into the accessory canal. Upon insertion, the gutta-percha point was pressed against the lingual wall of the main canal with a spreader (\#35), thus ensuring sufficient space in the main canal. The main canal was then coated with AH plus sealer (Dentsply) and obturated with calibrated \#35 (.04) gutta-percha point.

A post-operative radiograph shows a homogeneous and complete-to-the-apex root canal filling (Figs 2C, 5). Additional radiograph taken from the contralateral premolar revealed similar atypical premolar anatomy in tooth \#44 (Fig. 2D).

The teeth were restored with glass-ionomer (Ketac Molar, 3M ESPE) and light curing composite (Filtek Z550, 3M ESPE) following a strict adhesive protocol.

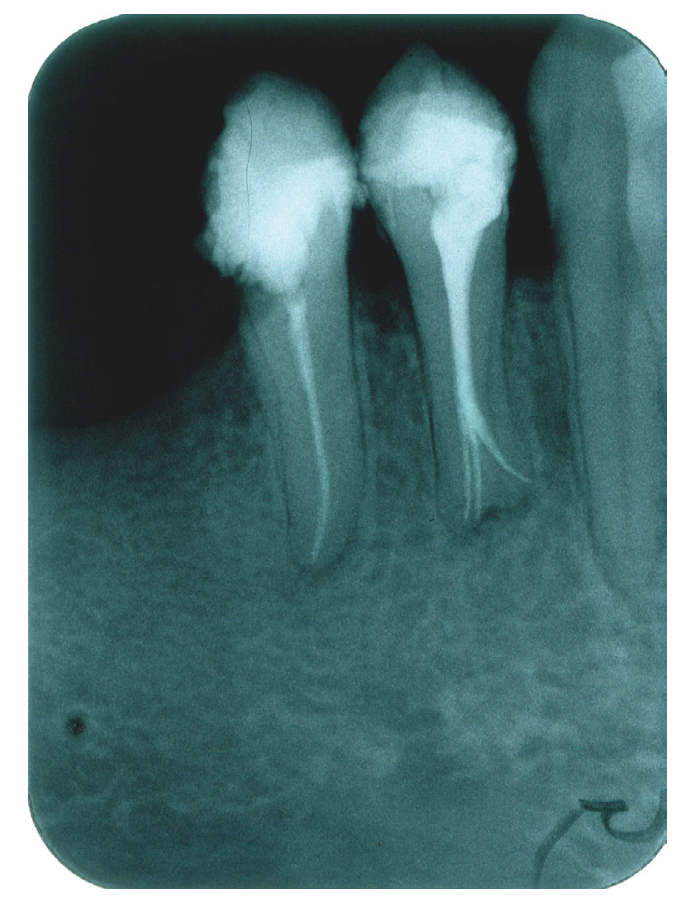

Figure 5. Postoperative radiograph: the main and accessory root canals have been successfully filled.

\section{DISCUSSION}

Endodontic treatment of mandibular premolars can be a challenging task in endodontics as they often manifest variable and aberrant anatomy of the root canal system. The percentage distribution of the number of roots and root canals in mandibular premolars varies in a wide spectrum. Vertucci et al. report the occurrence of one-root canal in one root in $70 \%$ of the mandibular first premolars and 
97.5\% of the second mandibular premolars (Vertucci type I). Presence of one root with two-root canals is reported in $1.5 \%$ of the mandibular first premolars and $0 \%$ in mandibular second premolars (Vertucci type IV). Cases of one root with one apically bifurcating root canal are present in $24 \%$ of the mandibular first premolars and $2.5 \%$ for mandibular second premolars (Vertucci type V). Bilateral type $\mathrm{V}$ root canal configuration is reported in the present case 1: one-root canal leaving the pulp chamber bifurcates in the apical third into two separate root canals, each with a separate apical foramen. ${ }^{8}$ The presented manual obturation protocol for the apically bifurcating root canal in clinical case 1 is simplified and provides optimal tactile feedback.

Findings of three-root canals with separate apical foramina in mandibular premolars are relatively rare. Research reports such canal configuration in second mandibular premolars as $0 \%$ and $0.4 \%$ in second maxillary premolars. $^{8,9}$

Partially and completely divided roots of lower premolars are named after CS Tomes (1889) who is credited as being the first to define this trait in the human dentition. Lower second premolars rarely exhibit bifurcated roots, so they are not usually scored for Tomes' root. ${ }^{10}$ Despite this fact, there are some reported cases of mandibular second premolars with two, three or even four roots. ${ }^{11,12}$

The success of endodontic treatment in teeth with aberrant root canal anatomy depends on the universal endodontic axiom: adequate root canal preparation; thorough disinfection; three-dimensional hermetic obturation of the canal; high quality coronal restoration. ${ }^{13}$ Short-cone (parallel) and long-cone (angulated) radiographic techniques as well as cone beam computer tomography (CBCT) prove to be essential aids in recognizing the deviant root canals. Accessory canals are often a challenge to observe in a conventional radiography. Frequent signs of accessory canal presence include sudden change in radiographic opacity or abrupt constriction of the root canal. ${ }^{14} \mathrm{~A}$ clinical cue to possible deviant root morphology in mandibular premolars is the diameter of the cervical zone below the cementoenamel junction - wider diameter often indicates presence of two or more root canals. ${ }^{7}$ More often, the endodontic access in teeth with anatomically deviant root canal system needs to be extensive in order to allow direct access of the endodontic instruments and sufficient visual control. Endodontic treatment of aberrant root canal system benefits greatly from the use of operative endodontic microscopes to provide detailed and directly magnified view of the root-canal system. ${ }^{15}$

\section{CONCLUSIONS}

Research and in-depth knowledge of the root-canal system provide the endodontist with better and more detailed understanding of the root-canal anatomy, as well as developing an anthropologic approach to its variety of aberra- tions. The report and description of rare clinical findings such as Tomes' root in a second mandibular premolar and apically bifurcated Vertucci type $\mathrm{V}$ root-canal system in a second mandibular premolar aims to contribute to systemizing the anatomical deviations of the root canal system and creation of unified protocols for treating these challenging cases.

\section{REFERENCES}

1. Vertucci FJ. Root canal morphology of mandibular premolars. J Am Dent Assoc 1978; 97:47-50.

2. Cantatore G, Berutti E, Castellucci A. Missed anatomy: frequency and clinical impact. Endod Topics 2006; 15(1):3-31.

3. Borna Z, Rahimi S, Shahi S, et al. Mandibular second premolars with three root canals: a review and 3 case reports. Iran Endod J 2011; 6(4):179-82

4. Cleghorn BM, Christie WH, Dong CC. The root and root canal morphology of the human mandibular second premolar: a literature review. J Endod 2007; 33(9):1031-7.

5. Vertucci FJ. Root canal anatomy of the human permanent teeth. Oral Surg Oral Med Oral Pathol Oral Radiol Endod 1984; 58:589-99.

6. De Moor RJ, Calberson FL. Root canal treatment in a mandibular second premolar with three root canals. J Endod 2005; 31(4):310-3.

7. Nallapati S. Three canal mandibular first and second premolars: a treatment approach. A case report. J Endod 2005; 31(6):474-6.

8. Vertucci FJ. Root canal anatomy of the human permanent teeth. Oral Surg Oral Med Oral Pathol Oral Radiol Endod 1984; 58:589-99.

9. Zillich R, Dowson J. Root canal morphology of mandibular first and second premolars. Oral Surg Oral Med Oral Pathol Oral Radiol Endod 1973; 36:738-44.

10. Scott GR, Turner CG. Description and classification II - Premolars. In: The anthropology of modern human teeth: dental morphology and its variation in recent human populations. 3rd ed. Cambridge, UK: Cambridge University Press; 2000. pp. 39-40.

11. Fathi Z, Rahimi S, Tavakoli R, et al. A three-rooted mandibular second premolar: A case report. J Dent Res Dent Clin Dent Prospects 2014; 8(3):184-6.

12. Milano M, Chavarria C, Hoppe J. Multi-rooted mandibular premolars: report of case. ASDC J Dent Child 2002; 69(1):63-5.

13. Schilder H. Cleaning and shaping the root canal. Dent Clin North Am 1974; 18:269-96.

14. Yu X, Guo B, Li KZ, et al. Cone-beam computed tomography study of root and canal morphology of mandibular premolars in a western Chinese population. BMC Medical Imaging 2012; 12(1):1-5.

15. Taschieri S, Del Fabbro M, Weinstein T, et al. Magnification in modern endodontic practice. Refuat Hapeh Vehashinayim 2010; 27(3):18-22. 


\title{
Девиантная морфология системы корневых каналов премоляров нижней челюсти: клинические случаи
}

\author{
Костадин Георгиев, Александра Печева \\ Кафедра оперативного зуболечения и эндодонтии, Факультет дентальной медицины, Медицинский университет - Пловдив, Пловдив, \\ Болгария
}

Адрес для корреспонденции: Костадин Георгиев, Кафедра оперативного зуболечения и эндодонтии, Факультет дентальной медицины, Медицинский университет - Пловдив, бул. „Христо Ботев“ № 3, Пловдив, Болгария; E-mail: kostadin.georgiev@mu-plovdiv.bg; Тел.: +359 883453823

Дата получения: 22 сентября 2020 Дата приемки: 13 января 2021 Дата публикации: 28 февраля 2022

Образец цитирования: Georgiev K, Pecheva A. Deviant morphology of the root canal system in mandibular premolars: clinical cases. Folia Med (Plovdiv) 2022;64(1):176-80. doi: 10.3897/folmed.64.e58877.

\section{Резюме}

Описаны многочисленные случаи аномальной морфологии корня и корневого канала, но чаще встречаются аномалии премоляров и моляров. Для стоматологии большой интерес представляют отклонения вторых премоляров нижней челюсти. В данном отчёте представлен клинический случай, представляющий собой упрощённый терапевтический протокол лечения корневых каналов V типа по классификации Vertucci. Эндодонтический доступ обеспечивается за счёт расширения эндодонтической полости. Инструментальную обработку (начальное расширение и окончательную подготовку) системы корневых каналов выполняют в основном с помощью ручных игл, чтобы максимально сохранить сенсорную реакцию в апикальной части ветви. Обтурация осуществляется методом гидравлической конденсации. Послеоперационные рентгенограммы показывают достаточное трёхмерное герметичное заполнение всех ответвлений канала с отличными терапевтическими результатами.

\section{Ключевые слова}

аберрантный корень, девиантная анатомия, Vertucci Тype V 